\title{
Neurotologic Complications Following Microvascular Decompression: A Retrospective Study
}

\author{
Matthew Bartindale ${ }^{1}$ Ayah Mohamed ${ }^{1}$ Jason Bell ${ }^{1}$ Matthew Kircher ${ }^{1}$ Jacqueline Hill ${ }^{2}$ \\ Douglas Anderson ${ }^{2}$ John Leonetti ${ }^{1}$
}

1 Department of Otolaryngology - Head and Neck Surgery, Loyola University Medical Center, Maywood, Illinois, United States

2 Department of Neurological Surgery, Loyola University Medical Center, Maywood, Illinois, United States

\begin{abstract}
Address for correspondence John Leonetti, MD, Department of Otolaryngology-Head and Neck Surgery, Loyola University Medical Center, Maguire Building, 2160 S. First Ave, Maywood, IL 60153, United States (e-mail: jleonet@lumc.edu).
\end{abstract}

J Neurol Surg B 2020;81:37-42.

\begin{abstract}
Objective The main purpose of this article is to determine the frequency of neurotologic complications after posterior fossa microvascular decompression (MVD) surgery.

Design Retrospective case review.

Setting Tertiary care referral center.

Participants A total of 215 consecutive MVD operations by a single surgeon between March 1996 and May 2016 were reviewed with 192 surgeries on 183 patients meeting inclusion criteria.

Main Outcome Measures Neurotologic complications secondary to MVD.

Results The 52 males and 131 females had a mean age of 58.52 years (range, 28-92

Keywords

- microvascular decompression

- cerebellopontine angle

- posterior fossa

- complications

- hearing loss

- tinnitus

- vertigo

- hemifacial palsy years). Indications for MVD were trigeminal neuralgia $(n=162)$, hemifacial spasm ( $n=23)$, glossopharyngeal neuralgia $(n=13)$, vagal palsy $(n=1)$, and tinnitus $(n=1)$. The outcomes examined were postoperative hearing loss, tinnitus, vertigo, and hemifacial paresis. At least one of these complications was present in $17.7 \%$ of patients. There were $4.17 \%$ with permanent hearing loss, $6.77 \%$ with transient hearing loss, $5.21 \%$ with tinnitus, $5.73 \%$ with vertigo, and $0.52 \%$ with hemifacial paresis. There was no significant difference in complication rates based on surgical indication.

Conclusions Neurotologic complications are a significant risk when performing MVD. It is important for otolaryngologists as well as neurosurgeons to be aware of such complications. We recommend perioperative audiometry in all patients undergoing MVD and believe there is utility in routine otolaryngologist involvement.
\end{abstract}

\section{Introduction}

Vascular compression of the nerve root exit zone ( $\mathbf{- F i g . 1}$ ) is characteristic of trigeminal neuralgia (TN), hemifacial spasm (HFS), and glossopharyngeal neuralgia (GPN). ${ }^{1,2} \mathrm{TN}$ is a chronic pain syndrome characterized by episodes of paroxysmal, lancinating pain accompanied by an electric shock sensation that affects one or more distributions of the fifth cranial nerve (CN V). Pain attacks can be triggered by typical daily activities such as chewing, brushing teeth, or drinking fluids. ${ }^{3}$ HFS

received

August 22, 2018

accepted after revision

December 5, 2018

published online

February 14, 2019

involves compression at the seventh $\mathrm{CN}$ and is characterized by involuntary, irregular, unilateral twitching of facial muscles. ${ }^{2}$ GPN manifests as sharp, stabbing pulses of pain in the auricular and pharyngeal regions caused by neurovascular compression at the root exit zone of the glossopharyngeal nerve. $^{1}$

The first line of treatment for TN, HFS, and GPN is pharmacotherapy. Medical management may initially yield a satisfactory response, but persistence or recurrence of symptoms and side effects of the medications can be too severe for some

(c) 2020 Georg Thieme Verlag KG Stuttgart · New York
DOI https://doi.org/ 10.1055/s-0039-1677688. ISSN 2193-6331. 


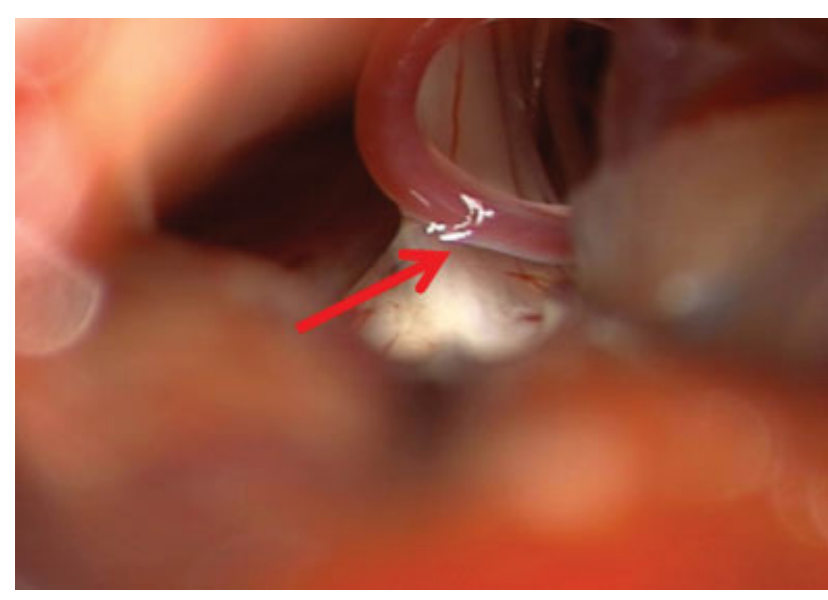

Fig. 1 Intraoperative image of neurovascular conflict (arrow).

patients to tolerate. For these patients, the next step in treatment may be surgical.

Jannetta demonstrated the efficacy of microvascular decompression (MVD) in 1967. ${ }^{4}$ The procedure involves correcting the neurovascular conflict by repositioning the offending vessel and placing spacer material between it and the affected $\mathrm{CN}^{2}$ This decompresses the nerve root exit zone and has been shown to ameliorate symptoms. A retrosigmoid approach has historically been used to approach the cerebellopontine angle (CPA). Other options such as balloon compression, rhizotomy, and radiosurgery are available, but MVD has been shown to be the procedure of choice for TN, ${ }^{5} \mathrm{HFS},{ }^{2,6}$ and GPN. ${ }^{1}$ MVD has also been shown to be effective for less common indications such as tinnitus and vagal palsy. ${ }^{7}$

MVD has consistently been validated with reports of high satisfaction rates and long-term results. ${ }^{8-12}$ However, some patients suffer from postoperative neurotologic complications such as hearing loss (HL), tinnitus, vertigo, and hemifacial paresis. ${ }^{13}$ Neurotologic complications are thought to be secondary to stretching of $\mathrm{CN}$ VII and VIII during cerebellar retraction, direct trauma to CN VII or VIII, excessive manipulation of vasculature (especially the labyrinthine artery and anteroinferior cerebellar artery), or neocompression of nerves with the spacer placement. ${ }^{14,15}$

There have been several studies that examined HL, but very few have evaluated tinnitus, vertigo, and hemifacial paresis. ${ }^{14,16}$ There is also a relative lack of studies distinguishing between transient, conductive hearing loss ( $\mathrm{CHL})$, and permanent sensorineural hearing loss (SNHL). Our study aims to determine the frequency of neurotologic complications after posterior fossa MVD in our past 20-year experience.

\section{Patients and Methods}

This study was approved by the Loyola University Medical Center (LUMC) Institutional Review Board (LU 208129). This retrospective study analyzed 215 consecutive patients who underwent posterior fossa MVD at LUMC between March 1996 and May 2016. The operations were all performed by a single neurosurgeon (DA). A stealth directed retrosigmoid craniotomy was used to access the CPA to identify the neurovascular conflict. After microdissection was performed, decompression was achieved by placing an autologous muscle graft or Teflon between the offending artery and $\mathrm{CN}$.

Patients were excluded if they had undergone previous radiosurgery, had a history of CPA tumor, had a previous surgery in the CPA other than MVD, or had follow-up of less than 2 weeks. A total of 32 patients were excluded based on these criteria. Neurotologic complications examined were HL, tinnitus, dizziness, and hemifacial paresis. During postoperative visits, patients were consistently asked about these conditions and $\mathrm{CN}$ exams were performed. Intraoperative brain stem auditory evoked potential monitoring and $\mathrm{CN}$ monitoring were not routinely used because of a perception that when HL occurred it was always transient. $p$-values for the comparison of complication rates were calculated using a two-tailed Fisher's exact probability test.

\section{Results}

Demographic data are displayed in -Table 1. A total of 192 surgeries were performed on 183 patients. In those patients who underwent revision operations, 13 of the primary MVD operations were performed at an outside institution, and nine were performed by the author (DA). Four patients had two ipsilateral surgeries, one patient had three ipsilateral surgeries, and one patient had three surgeries on one side and two on the other. In total, 34 patients had at least one neurotologic

Table 1 Demographics data

\begin{tabular}{|l|l|}
\hline Age $(n=183)$ & \\
\hline Range & $28-92$ years \\
\hline Mean \pm SD & $58.52 \pm 14.36$ years \\
\hline Sex $(n=183)$ & \\
\hline Male & 52 \\
\hline Female & 131 \\
\hline MVD indication $(n=200)^{a}$ & \\
\hline TN & 162 \\
\hline HFS & 23 \\
\hline GPN & 13 \\
\hline Vagal palsy & 1 \\
\hline Tinnitus & 1 \\
\hline Follow-up duration $(n=183)$ & \\
\hline Range & $0.5-208$ months \\
\hline Mean \pm SD & $35.42 \pm 47.21$ months \\
\hline Side of operation $(n=192)$ & \\
\hline Left & 95 \\
\hline Right & 97 \\
\hline MVD revision operations & 22 \\
\hline
\end{tabular}

Abbreviation: GPN, glossopharyngeal neuralgia; HFS, hemifacial spasm; MVD, microvascular decompression; SD, standard deviation; TN, trigeminal neuralgia.

${ }^{a} n$ is greater than the total number of surgeries because several patients had more than one indication for the same operation. 
Table 2 Summary of patients with permanent hearing loss

\begin{tabular}{|c|c|c|c|c|c|c|c|}
\hline Case no. & Age (years) & Sex & Laterality & Indication & HL type & AAO-HNS class & Follow-Up (months) \\
\hline 1 & 38 & $\mathrm{~F}$ & L & GPN & SNHL & B & 53 \\
\hline 2 & 39 & $\mathrm{~F}$ & $\mathrm{R}$ & HFS & SNHL & RA & 9 \\
\hline 3 & 50 & $\mathrm{~F}$ & $\mathrm{R}$ & HFS & Mixed & RA & 9 \\
\hline 4 & 87 & $\mathrm{~F}$ & $\mathrm{R}$ & $\mathrm{TN}$ & SNHL & $\mathrm{D}$ & 11 \\
\hline 5 & 52 & $\mathrm{~F}$ & L & $\mathrm{TN}$ & SNHL & $\mathrm{D}$ & 10 \\
\hline 6 & 77 & M & $\mathrm{R}$ & TN & SNHL & B & 22 \\
\hline 7 & 81 & $\mathrm{M}$ & $\mathrm{L}$ & TN & SNHL & $B$ & 4 \\
\hline 8 & 54 & $\mathrm{~F}$ & $\mathrm{~L}$ & $\mathrm{TN}$ & SNHL & B & 177 \\
\hline
\end{tabular}

Abbreviations: GPN, glossopharyngeal neuralgia; HFS, hemifacial spasm; RA, refused audiogram; SNHL, sensorineural hearing loss; TN, trigeminal neuralgia. AAO-HNS Class is based on no., number; AAO-HNS Class, American Academy of Otolaryngology Head and Neck Surgery guidelines for the evaluation of hearing preservation in vestibular schwannoma (-Fig. 3). ${ }^{17}$

complication postoperatively (17.71\%). There was no significant difference in risk for having a neurotologic complication between TN and HFS (relative risk $[\mathrm{RR}]=0.7704, p=0.5502$ ) or between primary and revision surgery $(\mathrm{RR}=0.4830$, $p=0.2934$ ). There were no complications for the patients whose indication for surgery was tinnitus $(n=1)$ or vagal palsy $(n=1)$.

\section{Hearing Loss}

Permanent SNHL was documented in eight cases (4.17\%). - Table 2 describes these cases in detail. All of these patients had at least 4 months of follow-up. The mean age for patients with HL was 59.75 years, with standard deviation 17.97 and range 38 to 87 years. Six were females and two were males. Indications for surgery were TN for five patients, HFS for two patients, and GPN for one patient (-Fig. 2). These all represented primary MVD. Two of the eight patients had preoperative audiograms, both of which were normal. Based on the 1995 American Academy of Otolaryngology-Head and Neck Surgery hearing classification system ( - Fig. 3), ${ }^{17}$ postoperative audiograms revealed that four patients were Class B and two were Class D (-Fig. 4). Case 7 had new bilateral HL which was slightly worse on the contralateral side. There was nothing exceptional that occurred during that operation and the etiology is unknown. Two patients refused an audiogram but significant ipsilateral $\mathrm{HL}$ was consistently documented.

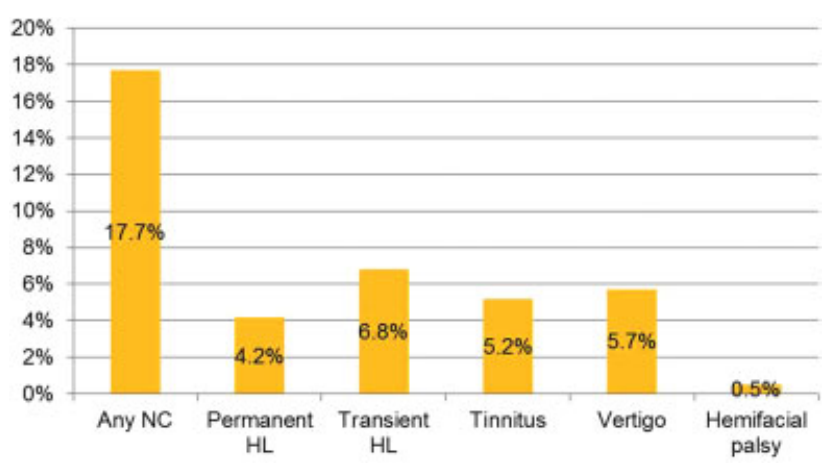

Fig. 2 Frequency of neurotologic complications. Abbreviations: HL, hearing loss; NC, neurotologic complication.

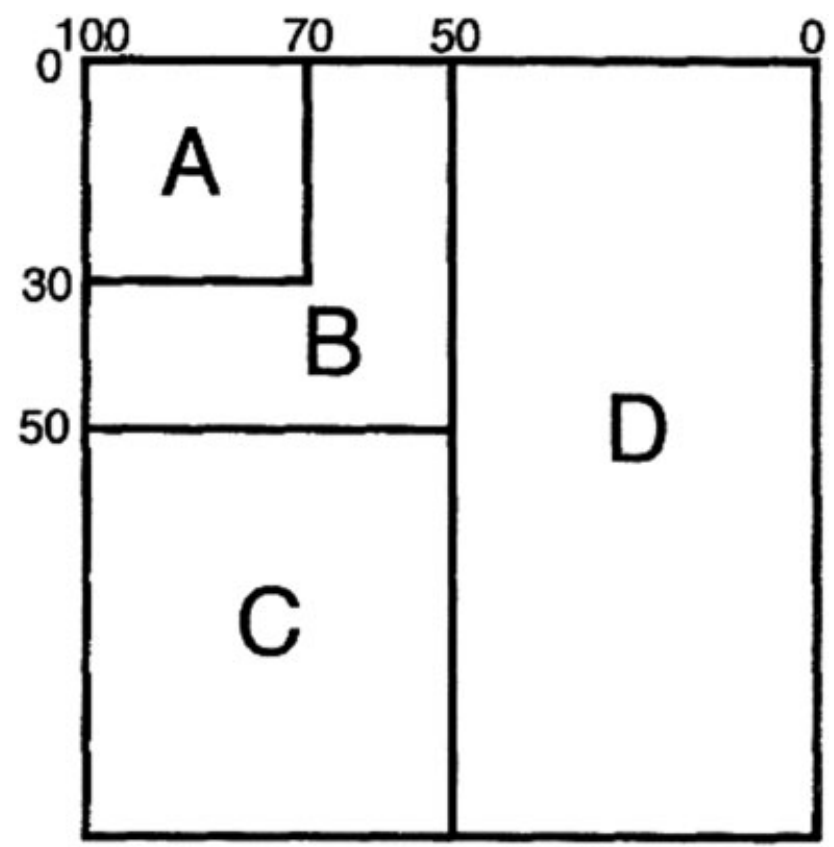

Fig. 3 Nomogram of the hearing classification system for the American Academy of Otolaryngology-Head and Neck Surgery guidelines for the evaluation of hearing preservation in vestibular schwannoma. ${ }^{17}$ Speech discrimination is along the horizontal axis and pure tone average is along the vertical axis.

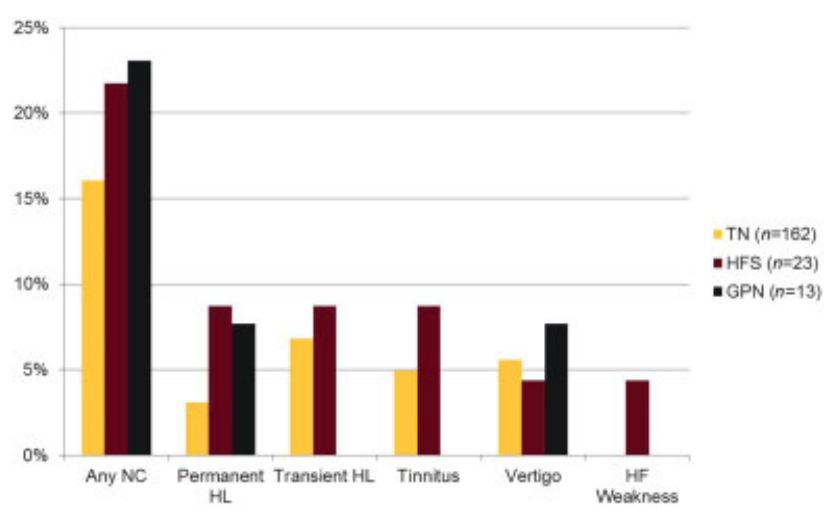

Fig. 4 Frequency of neurotologic complications by indication. Abbreviations: GPN, glossopharyngeal neuralgia; HF, hemifacial HFS, hemifacial spasm; $\mathrm{HL}$, hearing loss; NC, neurotologic complication; TN, trigeminal neuralgia. 
Thirteen patients had transient HL postoperatively (6.77\%). The mean age for these patients was 55.31 years, with standard deviation 11.85 years and range 37 to 74 years. Nine were females and four were males. Indications for surgery were TN for 11 patients, HFS for one patient, and both TN and HFS for one patient. These all represented primary MVD. The consistent complaints for these patients were aural fullness or muffled hearing. All complaints resolved within 4 weeks and none of the patients underwent an audiogram.

There were 12 patients who had a documented HL prior to surgery that remained stable postoperatively. Only five of these patients had preoperative audiograms in their medical record. The others denied worsening of their HL postoperatively.

There was no significant difference in risk for permanent $(\mathrm{RR}=0.3395, \quad p=0.1797)$ or transient $(\mathrm{RR}=1.4938$, $p=0.6938)$ HL between TN and HFS. There was also no significant difference in risk of HL between primary and revision surgery (permanent; $R R=0.4373, p=0.5652$, transient; $\mathrm{RR}=0.2754, p=0.3648$ ).

\section{Tinnitus}

Ten patients complained of tinnitus postoperatively (5.21\%). Five of those had associated HL (two permanent, three transient) and one had vertigo. The mean age for these patients was 58.40 years (standard deviation, 15.09 years; range, 37-77 years). Five were males and five were females. Two of these surgeries were revisions. Indications for surgery were TN for eight patients and HFS for two patients. Four additional patients had preoperative tinnitus which was stable postoperatively, including the patient whose indication for surgery was tinnitus. There was no significant difference in risk of postoperative tinnitus between TN and HFS ( $R R=0.5432, p=0.4203$ ) or primary and revision surgery $(R R=1.6970, p=0.4796)$.

\section{Vertigo}

Eleven patients complained of vertigo postoperatively (5.73\%). The vertigo was transient in five of the patients. One patient was later diagnosed with migraine-associated vertigo. Two of these patients had associated $\mathrm{HL}$ and one also had tinnitus. The mean age for these patients was 63.82 years, with standard deviation 12.15 years and range 38 to 83 years. Three were males and eight were females. None of the surgeries were revisions. Indications for surgery were TN for nine patients, HFS for one patient, and GPN for one patient. There was no significant difference in risk of postoperative vertigo between $\mathrm{TN}$ and HFS ( $R \mathrm{R}=1.3333$, $p=0.7803$ ) or primary or revision surgery $(\mathrm{RR}=0.3233$, $p=0.4289)$.

\section{Hemifacial Paresis}

One patient had hemifacial paresis postoperatively $(0.52 \%)$. He was a 65-year-old male who had primary MVD for HFS with postoperative ipsilateral House-Brackmann grade II facial weakness which has been stable over time. He also complained of tinnitus postoperatively.

\section{Discussion}

MVD offers effective, long-term symptom relief for patients with pathologies related to neurovascular conflicts of CNs in the posterior fossa. ${ }^{5}$ However, postoperative neurotologic complications such as HL, tinnitus, vertigo, and hemifacial paresis are serious complications which can significantly impact patients' quality of life. ${ }^{18}$ The complication rates in our study are similar to ranges reported in current literature. ${ }^{16,19,20}$

Following postauricular operations, effusions can frequently evolve in the middle ear leading to CHL. Patients describe this as muffled hearing or aural fullness. ${ }^{16}$ It is appropriate to wait at least 2 months postoperatively before pursuing an audiogram to allow a potential effusion to resolve. At that point, an audiogram should be performed with air and bone conduction thresholds. SNHL is far more likely to be permanent than CHL.

Injuries to the vestibulocochlear nerve or inner ear vasculature can also result in potentially disabling postoperative tinnitus. Tinnitus tends to correlate with HL, and patients will often complain of the ringing more than their HL. ${ }^{21,22}$ Since tinnitus often resolves in conjunction with HL, it is also appropriate to wait at least 2 months postoperatively before any intervention is pursued.

Patients may also experience vestibular dysfunction after CPA surgery, which may be temporary or permanent. In the short term, the patient may suffer from transient vertigo that prolongs the hospital stay. ${ }^{18}$ In the long term, the patient may note persistent imbalance, made worse with fatigue, alcohol consumption, and visual loss.

Hemifacial paresis is another complication that can occur after MVD. While considerably less common than the other neurotologic complications, it can be the most distressing to patients. Corticosteroid treatment is recommended in these patients; however, their efficacy after MVD is unclear at this point. ${ }^{23,24}$

There was no significant difference in complication rates between TN and HFS. It is logical to expect that HFS would have a higher complication rate given its closer proximity to both the CN VII/CN VIII bundle and the inner ear vasculature. It is possible that in a study with a larger sample size a significant difference would be revealed.

While some neurotologic complications are inevitable, all possible measures to minimize their occurrence and severity should be undertaken. This includes limiting cerebellar retraction, minimizing trauma to CN VII and VIII, and protecting vessels that are important for inner ear function. ${ }^{25}$ There was a single case which resulted in contralateral HL (Case 7). This has been reported in the literature after MVD and may be secondary to intraoperative brain stem shift, brain stem edema, or venous congestion at the ipsilateral inferior colliculus. ${ }^{14,26}$ Utilizing intraoperative monitoring of brain stem auditory evoked potentials has generally been shown to decrease the risk of hearing impairment after MVD. ${ }^{27,28}$ It is possible that the HL incidence in this study would have been lower if brain stem auditory evoked potentials had been used. After this data was collected, we have begun to routinely use brain stem auditory evoked potentials at our institution. 
To underscore the importance of appropriate preoperative audiometric documentation, twelve of our patients had written documentation of preoperative HL, but only five had preoperative audiograms to quantify this loss. The lack of a preoperative audiogram for the other seven patients made it impossible to objectively assess whether their postoperative HL was stable, worse, or improved. Insufficient perioperative audiometric evaluation in such cases leaves neurosurgeons vulnerable to medicolegal ramifications in situations where they may not have even caused a supposed complication. To prevent this, it is critical that perioperative audiograms are performed on a routine basis. The incidence of HL in this study may have been higher if perioperative audiograms had been performed on all of the patients.

Counseling patients before surgery to ensure understanding of the neurotologic risks of undergoing MVD is critical. It is also important to monitor patients postoperatively for these complications with thorough histories and physical exams. We recommend an audiogram within 6 months before surgery and then another 2 to 3 months postoperatively in all patients.

\section{Conclusion}

MVD carries significant risks of neurotologic complications such as HL, tinnitus, vertigo, and hemifacial paresis. We emphasize the importance of evaluating perioperative audiometric function and ensuring patient understanding of potential neurotologic complications following MVD.

Note

This paper was presented as an oral presentation at the American Academy of Otolaryngology Annual Meeting in San Diego, California on September 20, 2016.

\section{Conflict of Interest}

None.

Acknowledgments

We have no acknowledgments.

\section{References}

1 Gaul C, Hastreiter P, Duncker A, Naraghi R. Diagnosis and neurosurgical treatment of glossopharyngeal neuralgia: clinical findings and 3-D visualization of neurovascular compression in 19 consecutive patients. J Headache Pain 2011;12(05):527-534

2 Qi H, Zhang W, Zhang X, Zhao C. Microvascular decompression surgery for hemifacial spasm.J Craniofac Surg 2016;27(01):124-127

3 Devor M, Amir R, Rappaport ZH. Pathophysiology of trigeminal neuralgia: the ignition hypothesis. Clin J Pain 2002;18(01):4-13

4 Jannetta PJ. Arterial compression of the trigeminal nerve at the pons in patients with trigeminal neuralgia. J Neurosurg 1967;26 (1, 1part2):159-162

5 Sarsam Z, Garcia-Fiñana M, Nurmikko TJ, Varma TRK, Eldridge P. The long-term outcome of microvascular decompression for trigeminal neuralgia. Br J Neurosurg 2010;24(01):18-25

6 Hitchon PW, Zanaty M, Moritani T, et al. Microvascular decompression and MRI findings in trigeminal neuralgia and hemifacial spasm. A single center experience. Clin Neurol Neurosurg 2015; 139:216-220

7 Zhang L, Yu Y, Yuan Y, Xu J, Xu X, Zhang J. Microvascular decompression of cochleovestibular nerve in patients with tinnitus and vertigo. Neurol India 2012;60(05):495-497

8 McLaughlin MR, Jannetta PJ, Clyde BL, Subach BR, Comey CH, Resnick DK. Microvascular decompression of cranial nerves: lessons learned after 4400 operations. J Neurosurg 1999;90(01):1-8

9 Barker FG II, Jannetta PJ, Bissonette DJ, Larkins MV, Jho HD. The long-term outcome of microvascular decompression for trigeminal neuralgia. N Engl J Med 1996;334(17):1077-1083

10 Oesman C, Mooij JJ. Long-term follow-up of microvascular decompression for trigeminal neuralgia. Skull Base 2011;21(05):313-322

11 Jagannath PM, Venkataramana NK, Bansal A, Ravichandra M. Outcome of microvascular decompression for trigeminal neuralgia using autologous muscle graft: a five-year prospective study. Asian J Neurosurg 2012;7(03):125-130

12 Burchiel KJ, Clarke H, Haglund M, Loeser JD. Long-term efficacy of microvascular decompression in trigeminal neuralgia. J Neurosurg 1988;69(01):35-38

13 Huh R, Han IB, Moon JY, Chang JW, Chung SS. Microvascular decompression for hemifacial spasm: analyses of operative complications in 1582 consecutive patients. Surg Neurol 2008;69(02): 153-157, discussion 157

14 Park K, Hong SH, Hong SD, Cho Y-S, Chung W-H, Ryu NG. Patterns of hearing loss after microvascular decompression for hemifacial spasm. J Neurol Neurosurg Psychiatry 2009;80(10):1165-1167

15 Lee MH, Lee HS, Jee TK, et al. Cerebellar retraction and hearing loss after microvascular decompression for hemifacial spasm. Acta Neurochir (Wien) 2015;157(02):337-343

16 Shah A, Nikonow T, Thirumala P, et al. Hearing outcomes following microvascular decompression for hemifacial spasm. Clin Neurol Neurosurg 2012;114(06):673-677

17 Committee on Hearing and Equilibrium guidelines for the evaluation of hearing preservation in acoustic neuroma (vestibular schwannoma). American Academy of Otolaryngology-Head and Neck Surgery Foundation, INC. Otolaryngol Head Neck Surg 1995; 113(03):179-180

18 Heuser K, Kerty E, Eide PK, Cvancarova M, Dietrichs E. Microvascular decompression for hemifacial spasm: postoperative neurologic follow-up and evaluation of life quality. Eur J Neurol 2007;14(03):335-340

19 Møller MB, Møller AR. Loss of auditory function in microvascular decompression for hemifacial spasm. Results in 143 consecutive cases. J Neurosurg 1985;63(01):17-20

20 Chung SS, Chang JH, Choi JY, Chang JW, Park YG. Microvascular decompression for hemifacial spasm: a long-term follow-up of 1,169 consecutive cases. Stereotact Funct Neurosurg 2001;77 (1-4):190-193

21 Li D, Wang H, Fan Z, Fan Z. Complications in retrosigmoid cranial nerve surgery. Acta Otolaryngol 2010;130(02):247-252

22 Youn J, Kwon S, Kim JS, Jeong H, Park K, Cho JW. Safety and effectiveness of microvascular decompression for the treatment of hemifacial spasm in the elderly. Eur Neurol 2013;70 (3-4):165-171

23 Rhee DJ, Kong DS, Park K, Lee JA. Frequency and prognosis of delayed facial palsy after microvascular decompression for hemifacial spasm. Acta Neurochir (Wien) 2006;148(08):839-843, discussion 843

24 Lee J, Fung K, Lownie SP, Parnes LS. Assessing impairment and disability of facial paralysis in patients with vestibular schwannoma. Arch Otolaryngol Head Neck Surg 2007;133(01):56-60

25 Ying T, Thirumala P, Chang Y, Habeych M, Crammond D, Balzer J. Empirical factors associated with brainstem auditory evoked potential monitoring during microvascular decompression for hemifacial spasm and its correlation to hearing loss. Acta Neurochir (Wien) 2014;156(03):571-575 
42 Neurotologic Complications Following MVD Bartindale et al.

26 Strauss C, Naragi R, Bischoff B, Huk WJ, Romstöck J. Contralateral hearing loss as an effect of venous congestion at the ipsilateral inferior colliculus after microvascular decompression: report of a case. J Neurol Neurosurg Psychiatry 2000;69(05):679-682

27 Polo G, Fischer C, Sindou MP, Marneffe V. Brainstem auditory evoked potential monitoring during microvascular decompression for hemifacial spasm: intraoperative brainstem auditory evoked potential changes and warning values to prevent hearing loss-prospective study in a consecutive series of 84 patients. Neurosurgery 2004;54(01):97-104, discussion 104-106

28 Joo BE, Park SK, Cho KR, Kong DS, Seo DW, Park K. Real-time intraoperative monitoring of brainstem auditory evoked potentials during microvascular decompression for hemifacial spasm. J Neurosurg 2016;125(05):1061-1067 